\title{
Fabrication of Self-Aligned Multilevel Nanostructures
}

\author{
Praveen Joseph ${ }^{\text {a,* }}$, Shrawan Singhal a , Ovadia Abed ${ }^{a}$, S. V. Sreenivasan ${ }^{\text {a,b }}$ \\ ${ }^{a}$ NASCENT Center, 10100 Burnet Road, The University of Texas at Austin, Austin, TX 78758, United States \\ ${ }^{b}$ Canon Nanotechnologies, Inc., 1807 West Braker Lane, C-300, Austin, TX 78758, United States
}

\begin{abstract}
Multilevel three-dimensional nanostructures are essential in many integrated nanoelectronic and nanophotonic applications. With the continued shrinking of critical device dimensions, extremely precise nanoscale overlay is required between multiple individual levels of these integrated devices.Multilevel nanoimprint lithography has been proposed in the literature as a potential solution to this overlay problem. In this context, self-aligned (perfectly aligned)multileveltemplates (SAMT) for multilevel nanoimprint lithography are proposedin this article. By combining nanolithography, atomic layer deposition, and highly selective reactive ion etch, SAMTs canenable the fabrication of sophisticated integrated devices.Four specific self-aligned multilevel fabrication techniques have been demonstrated that result in symmetric multilevel structures, bilaterally symmetric multilevel structures, tubular structures, and asymmetric multilevel structures, all in the sub-100nm scale. When used in conjunction with a nanoimprint lithography process, the SAMTs can enable highthroughput patterning of various nanoelectronic and nanophotonic devices using a single patterning step with perfect alignment and overlay.SAMTs further enable large area patterning, such as wafer-scale patterning and roll-to-roll patterning on flexible substrates, without compromising perfect overlay.
\end{abstract}

Keywords: Nanoimprint Lithography, Multilevel Patterning, 3D Patterning, Self-Aligned Patterning, Atomic Layer Deposition, Multiple Patterning, Pattern Transfer, SADP.

\section{INTRODUCTION}

As critical device dimensions continue to scale aggressively in keeping with Moore's Law, fundamental limits to feature resolution are being reached for several state-of-the-art topdown nanopatterning techniques, thus constraining the performance as well as the packing density of the devices. For example, a typical $193 \mathrm{~nm}$ immersion (193i nm) optical lithography process has an ultimate achievable imaging resolution of $\sim 36 \mathrm{~nm}$ [1]. For some of the most advanced devices in nanoelectronicsthat have feature dimensions smaller than this limit[2], several techniques,such as double patterning, optical proximity correction, and phase shift masks have beenused.These result in significant increase in cost due to the greater number of subsequent non-lithographic process steps [3-5]. At the same time, directed self-assembly (DSA) techniques are being explored to complement 193i nm lithography, especially for via hole shrink applications[5][10].However, these techniques are limited to periodic patterns and have problems with long-range order. Likewise, significant challenges remain with electron beam [11] based

\footnotetext{
${ }^{*}$ Corresponding author.

Email address:praveenjoseph@utexas.edu (P. Joseph).
}

techniques, such as multiple e-beam lithography (MEBL), and other higher resolution photon beam based techniques, such as extreme ultraviolet lithography (EUVL) [12]-[15].

Also, all the above techniques have been developed for patterning substantially planar layouts on the surface of a rigid substrate. They cannot be directly translated to nanoscale patterning on non-traditional substrate configurations, such as flexible substrates in a roll-to-roll format or across entire wafers beyond a smaller patterning field. They are also typically unable to pattern non-planar, three-dimensional structures in a single step. These structuresare being explored to overcome fabrication complexity, packing density and performance constraints of standard surface-patterned devices. For example, three-dimensional FinFETs have been demonstrated to have highly desirable properties while not compromising with packing density constraints[16]-[18]. Similarly, three-dimensional photonic crystals allow for enhanced functional characteristics compared to traditional two-dimensional designs[19]. However, their fabrication requires that each level in suchmultilevel three-dimensional devices,is patterned individually, thus placing extremely stringent constraints on level-to-level alignment.

In this regard, nanoimprint lithography [20] - [24] has been demonstrated as a high throughput, low-cost lithographic technique capable of patterning arbitrary geometries with demonstrated sub-10 $\mathrm{nm}$ feature resolution. Moreover, multilevel imprint lithography has been demonstrated to pattern multilevel structures with high-fidelity by replicating an existing multilevel pattern on the template [25-28]. Since the multilevel pattern is pre-coded in the template geometry, multilevel imprint lithography can lend itself to faithful and cost-effective replication of the same geometry without needing further alignment or overlay. But, such demonstrations have only been carried out with micron-scale resolution.Hence, the goal of this work, is to enable multilevel imprint lithography with nanoscale resolution and perfect alignment between individual levels.

\section{Motivation}

One of the challenges associated with fabrication of multilevel three-dimensional structures with traditional patterning techniques is the need for precise level-to-level alignment. Misalignment gives rise to the problem of nanoscale overlay, which refers to the accuracy with which a patterned field can be registered relative to a previously lithographed field. Overlay requirement is typically one-half to one-quarter of the minimum feature size [23], which can be extremely tight for features in the sub-20 nm regime. The current best achievable overlay with nanoimprint lithography is $10 \mathrm{~nm}($ mean $+3 \sigma)$ over a field size of $26 \mathrm{~mm} \times 33 \mathrm{~mm}$ [29]. This problem of overlay is exacerbated when imprinting on 
flexible substrates, that have significant distortion, or over extremely large areas in a single step on rigid substrates [30]. With multilevel nanoimprint lithography using a template with nanoscale features, this can be overcome. However, the nanoimprint template now needs to be fabricated with precise level-to-level alignment over large areas. In previous demonstrations of multilevel imprint lithography [25]-[28], [31]-[39], individual levels on the imprint template were fabricated using multiple optical or electron beam lithography steps. This limits the best possible overlay that can be achieved between consecutive levels due to inherent tool limitations. Overcoming this overlay constraint by fabricating self-aligned multilevel nanoimprint lithography templates (SAMTs) is the key motivation behind this work. The methodology for fabrication of SAMTs is described in Section III.

For validation of the benefits ofperfect level-level alignment, three exemplar deviceshave been identified. The first device relates to a NMOS transistor array, which can be patterned in a single step across large areas if a SAMT is used. The optimum geometry for such a SAMT is shown in Fig. 1(a). The process of using this SAMT to fabricate wafer-scale NMOS arrays is discussed in Appendix A [40].This SAMT can in turn, be fabricated using a bilaterally symmetric multilevel geometry highlighted by the red rectangleand illustrated in Fig. 1(b) [28], [40]. A self-aligned process to fabricate such bilaterally symmetric multilevel structures (Fig. 1(b)) is demonstrated in Section IV.

The second exemplar device is a nanotube capacitor, for which the geometry is shown in Fig. 2. In previous work[41], [42], it has been shown that the performance of nanoscale capacitors depends on the surface area. With the use of multilevel patterning and perfect alignment, solid circular cross-sections of these capacitors can be enhanced into hollow tubular cross-sections. This increases the surface area dramatically, thereby increasing the unit capacitance of such devices[43]. Demonstration of self-aligned Si tube structures is discussed in Section V.

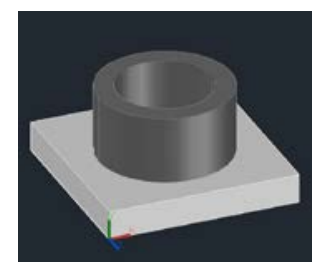

Fig.2.Illustration of self-aligned Si tubes for fabrication Si tube capacitors

The third device that can benefit from multilevel imprinting is a metamaterial wire-grid polarizer (WGP). Through modeling using the finite difference time domain (FDTD) technique and geometricoptimization using genetic algorithms [40],it can be observed that the use of certain asymmetric multilevelgrating structures, shown in Fig. 3,enhance the extinction ratio of these devices. Such structures can then enable high-performance nanophotonic devices with costeffective fabrication on flexible substrates [44], [45] for high density displays. The process of fabricating asymmetric multilevel nanostructuresis demonstrated in Section VI.

\section{METHODOLOGY}

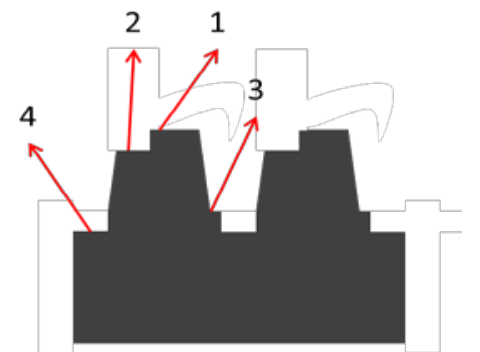

Fig.3.Illustration of a cross section of asymmetric multilevel grating structures for fabrication of high performance metamaterial wire-grid polarizers

In this section, a general outline of the processes used in the fabrication of multilevel nanostructures is discussed in the context of fabricating SAMTs. The primary advantage of nanoimprinting using SAMTs compared to $193 \mathrm{i} \mathrm{nm}$ lithography, is the patterning of precisely aligned multilevel features without the need for nanoscale overlay, in one patterning step. The general methodology for fabrication of SAMTs relies on a combination of nanoscale lithography, atomic layer deposition's (ALD) atomic precision, and highly etch selective material choices, to ensure precise selfalignment of multiple levels in the nanoscale (Fig. 4). The red box encloses the unit processes that enable fabrication of SAMTs which forms the novel contribution of this work. The methodology has been first validated for symmetric multilevel nanostructures. The subsequent sections present other techniques that draw from the theme presented in this section to fabricate 3D shapes identified earlier in Section II and given in Figures 1-3.The nanoscale lithography technique used in this research for fabrication of SAMTs is a variant of wafer scale UV nanoimprint lithography, called Jet-and-Flash Imprint Lithography (J-FIL ${ }^{\mathrm{TM}}$ ) (Fig. 5) [23]. At the same time, the SAMTs have also been fabricated to be compatible with the J-FIL process.

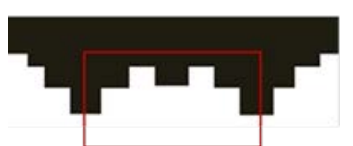

(a)

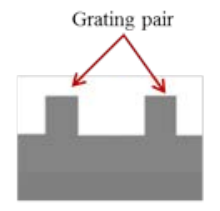

(b)
Fig. 1.Illustration of (a) nanoimprint replica template for fabrication of NMOS arrays on a wafer-scale (b) bilaterally symmetric multilevel structure on master template highlighting the geometry within the red rectangle in (a) 


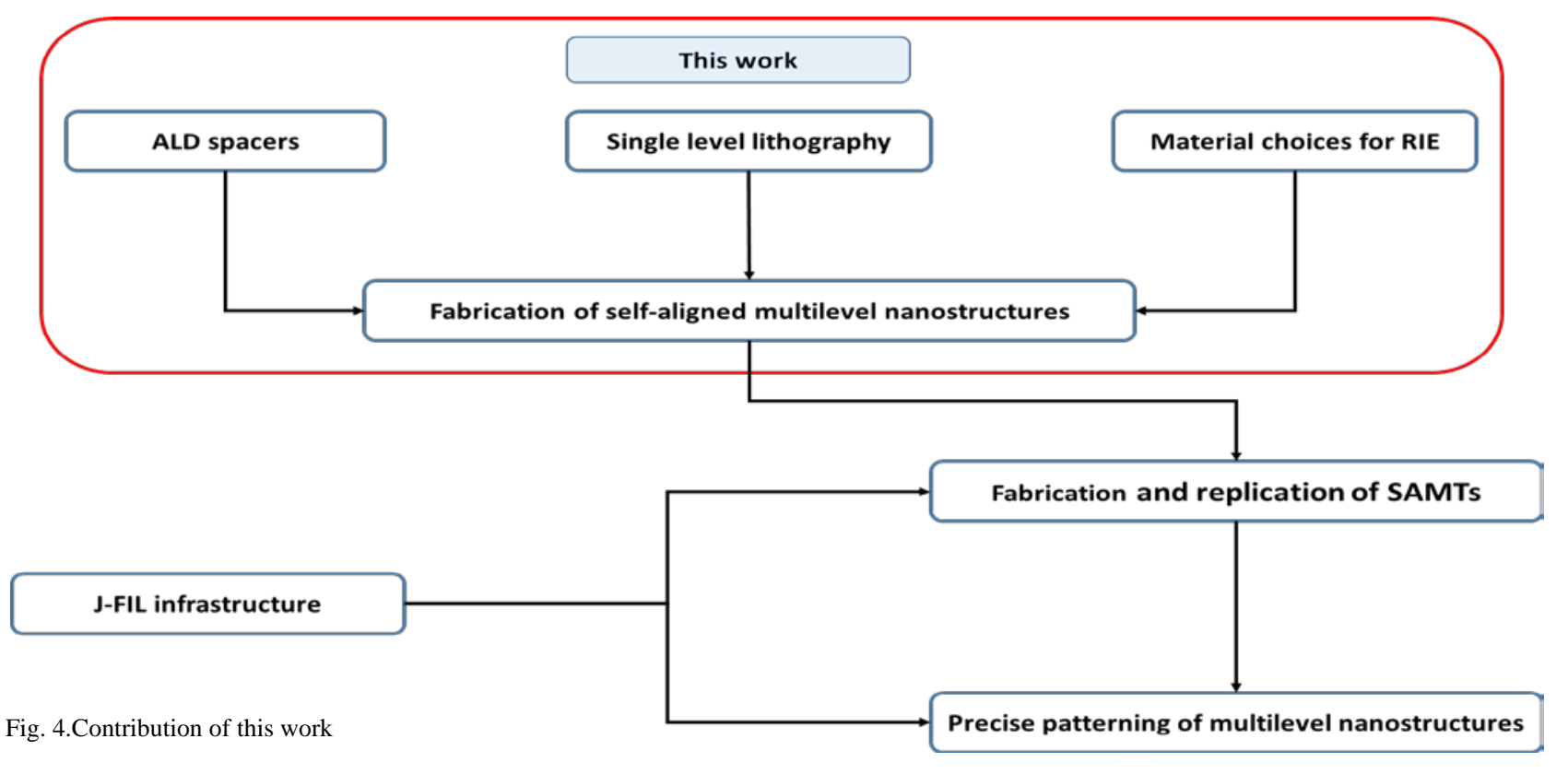

remaining resist mask as shown in Fig. 8(b).

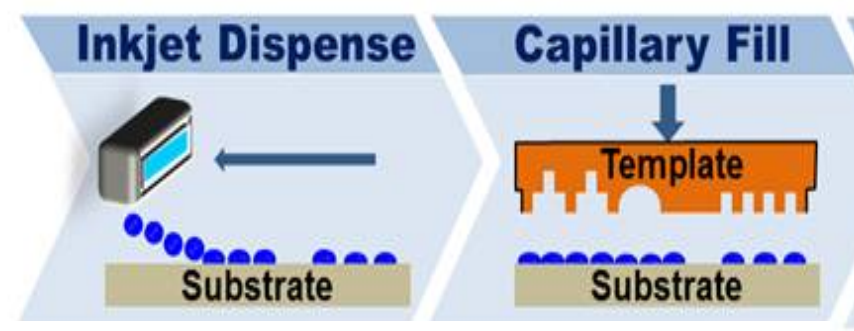

Fig. 5. Jet and Flash Imprint Lithography (J-FIL) Process [23]

\section{A. Self-Aligned Symmetric Multilevel Structures}

The structure illustrated in Fig. 6is a symmetric multilevel geometry, similar to that used in the dual damascene work for copper interconnects [16-17, 27]. A selfaligned technique to fabricate such shapes is used to validate the techniques developed in this research.

J-FIL templates for large area patterning are typically fabricated on $150 \mathrm{~mm}$ diameter fused silica wafers. In this work, instead of fused silica, the experiments are conducted using $\mathrm{Si}$ wafers with $\mathrm{SiO}_{2}$ deposited by thermal oxidation or by plasma enhanced chemical vapor deposition (PECVD). Etch processes developed for this stack can be directly translated to fused silica. Moreover, fused silica replica templates can also be fabricated from master Si templates with multilevel shapes using the process described in [28]. An illustration of the technique used here is shown in Fig. 7. The first step in the process is patterning $65 \mathrm{~nm}$ half-pitch gratings using J-FIL over a circular area of $80 \mathrm{~mm}$ diameter (experimental details are provided in Section VII). Micrographs of the imprinted resist pattern are shown in Fig. 8(a). This is followed by reactive ion etching (RIE) of the residual resist layer. The resist pattern is used as a mask to etch into $\mathrm{SiO}_{2}$ using RIE. After obtaining the desired etch depth in $\mathrm{SiO}_{2}$, a standard piranha clean is used to remove the

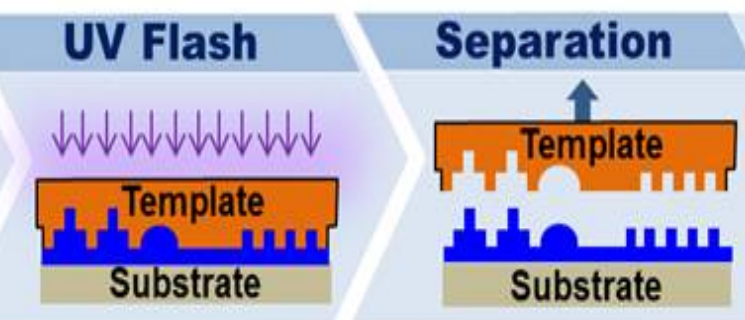



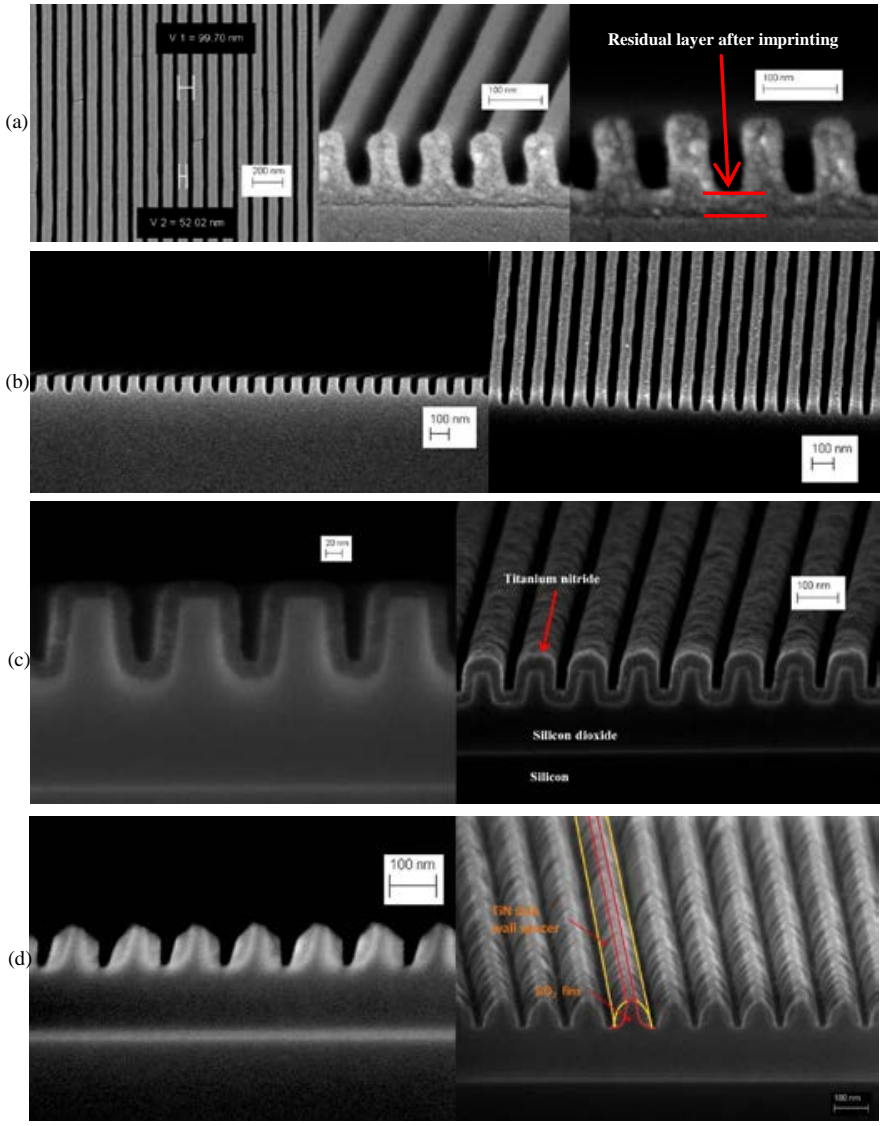

Fig. 8. Scanning electron micrographs of:(a) imprinted 50nm half-pitch grating pattern. Left: top view showing grating pitch of $100 \mathrm{~nm}$ - scale bar is $200 \mathrm{~nm}$; Middle:30 degree tilted view - scale bar is $200 \mathrm{~nm}$; Right:cross section view showing residual layer $\sim 23 \mathrm{~nm}-$ scale bar is 100nm; (b) etched $\mathrm{SiO}_{2}$ after the resist mask has been stripped. Left: cross section view; Right:30 degree tilted view - scale bar in both images is $100 \mathrm{~nm}$; (c) conformal TiNdeposited by ALD on patterned $\mathrm{SiO}_{2}$.Left: cross section view - scale bar is 20nm;Right: 10 degree tilted view - scale bar is $100 \mathrm{~nm}$; (d) TiN side wall spacers. Left: cross section view; Right:30 degree tilted view with side wall spacers and oxide features marked along grating direction - scale bar in both images is $100 \mathrm{~nm}$

A conformal layer of spacer material is then deposited on the patterned $\mathrm{SiO}_{2}$ using ALD. Titanium nitride (TiN) is chosen as the spacer material because of its high RIE and wet etch selectivity to $\mathrm{SiO}_{2}$ and ability to be deposited using ALD. Fig. 8(c) is a micrograph showing conformal TiN spacer material deposited on $\mathrm{SiO}_{2}$ grating using ALD.Previous work on inductively coupled plasma (ICP) etching of TiN using $\mathrm{Cl}_{2} / \mathrm{Ar}$ chemistry for micron-scale features [46], has been modified to define the required TiN nanoscale sidewall spacers and open up the trenches between the $\mathrm{SiO}_{2}$ gratings as shown in Fig. 8(d). The TiN spacers serve as etch masks for RIE of second level $\mathrm{SiO}_{2}$ etching. Piranha clean is then used to remove TiN spacers and organic contaminants from the surface of the selfaligned symmetric multilevel $\mathrm{SiO}_{2}$ grating pattern. This reveals the symmetric multilevelself-aligned nanostructures (Fig. 9), in which $65 \mathrm{~nm}$ wide grating features on top of 100 $\mathrm{nm}$ wide lower level grating features have been successfully demonstrated with an equal spacing of $18 \mathrm{~nm}$ on either side of the top grating. This perfect centering of the top grating on the lower grating is possible due to the conformal nature of the
ALD process.

The process described here can be applied to other nanogeometries. For instance, if the initial geometry patterned are pillars instead of gratings, a similar fabrication process would yield multilevel pillars. Using a combination of etch optimizations for oxide etch depths and TiN spacer widths, this process can be used to form variations of multilevel precisely aligned nanopillar/nanodisc structures as shown in the SEM images in Fig. 10.

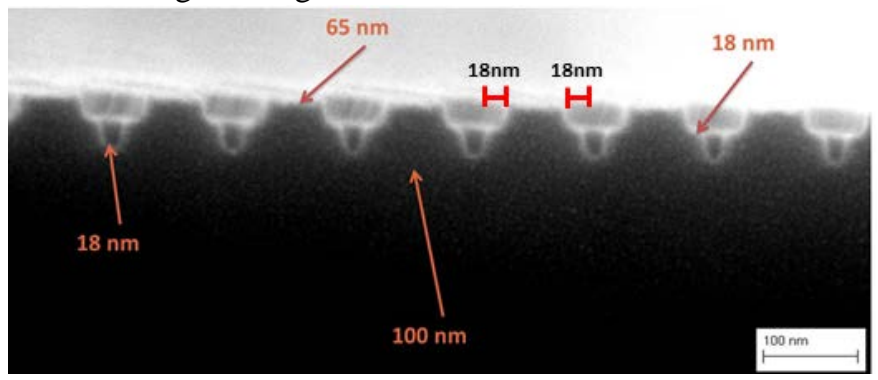

Fig. 9. Scanning electron micrograph of sub-100nm symmetric multilevel nanostructures in $\mathrm{SiO}_{2}$. Scale bar is $100 \mathrm{~nm}$.

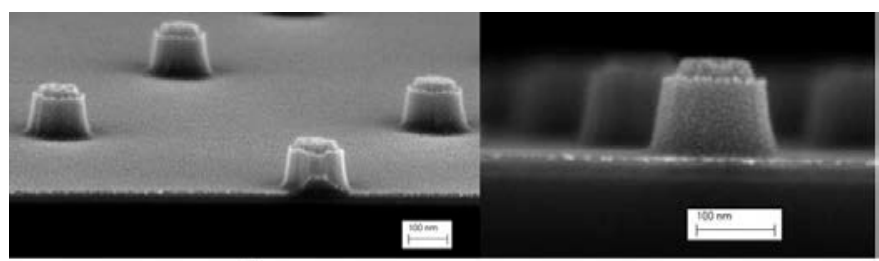

(a)

(b)

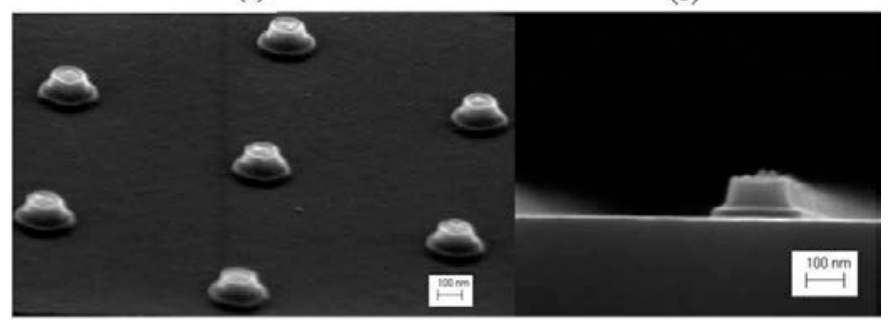

(c)

(d)

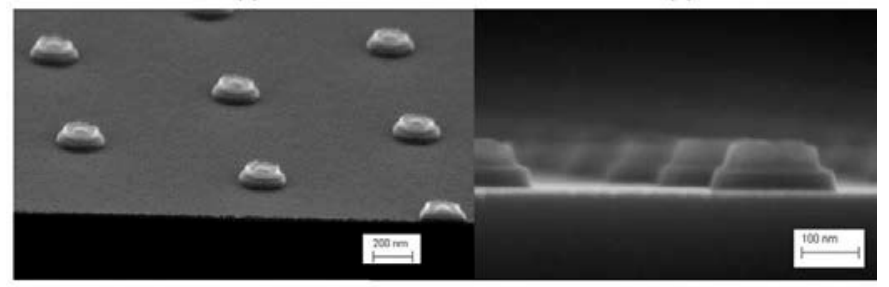

(e)

(f)

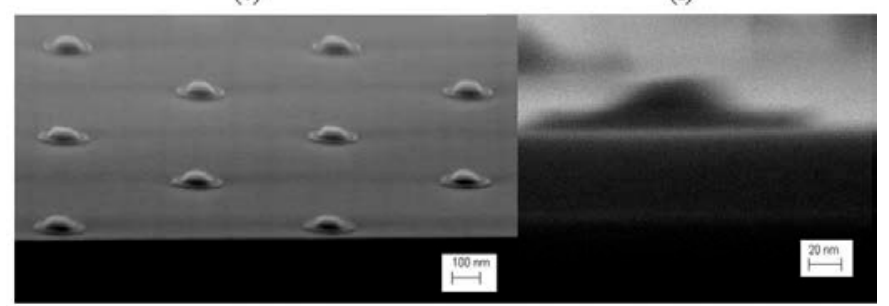

(g)

(h)

Fig. 10. Scanning electron micrographs of variations of multilevelnanopillars/nanodiscs fabricatedusing varying ratios of the same etch chemistry. Figures (a), (c), (e), (g) are 25 degree tilted views and figures (b), (d), (f), (h) are corresponding cross section views. Scale bars in images (a), (b), (c), (d), (f), (g) are 100nm; scale bar in image (e) is $200 \mathrm{~nm}$; scale bar in image (h) is $20 \mathrm{~nm}$. 


\section{Bilaterally Symmetric MultileVel Structures}

The structure illustrated in Fig. 1(b) is a bilaterally symmetric multilevel grating structure. Such a structure with precise alignment of levels can enable large area fabrication of transistor structures as shown in [40]. An ALD based selfalignment process to fabricate a SAMT with this structure is shown next.

Because of the unavailability of J-FIL templates with the desired starting structure of a paired nanoscale grating (shown in step 1 of Fig. 11), e-beam lithography has been used to

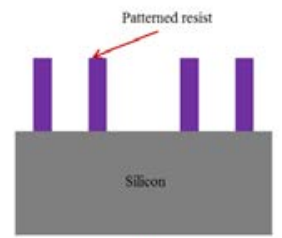

(1)

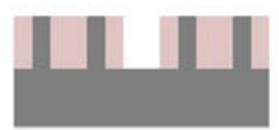

(4)

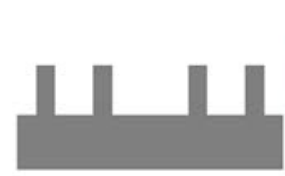

(2)

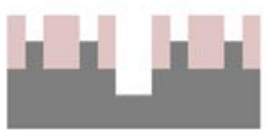

(5)

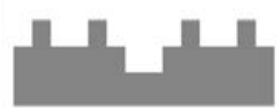

(6)
Fig. 11. Illustration of a method to fabricate bilaterally symmetric multilevel structures.

define the pattern on a $\mathrm{Si}$ wafer. Following this, pattern transfer by RIE into Si using the resist mask is carried out and the remaining resist mask can be removed by piranha cleaning.SEM of the resulting grating structure is shown in Fig. 12(a). This is followed by ALD of a sidewall spacer material such that the distance between the two gratings in a pair is filled as shown in step 3 of Fig. $11 . \mathrm{SiO}_{2}$ is used as the spacer material because of its high RIE and wet etch selectivity with Si and ability to be deposited using ALD. An SEM image of the resulting structure is shown in Fig. 12(b). Blanket etching of the $\mathrm{SiO}_{2}$ ALD film is carried out next in order to expose Si between the pairs (but not within the pair itself) of gratings as shown in step 4 .

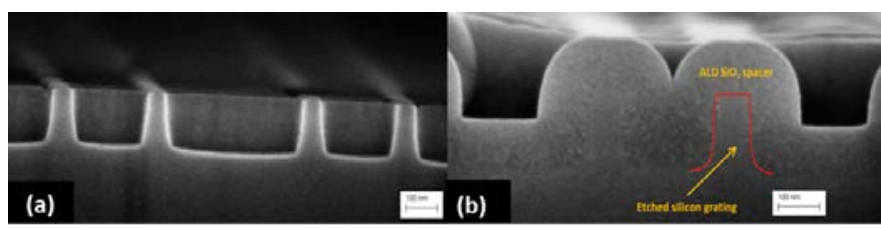

Fig. 12. Cross-sectional scanning electron micrograph showing(a) grating pairs etched into $\mathrm{Si}$; (b) ALD of $\mathrm{SiO}_{2}$ on Si grating pairs - SEM scale bar is $100 \mathrm{~nm}$ in both images.

At this stage, the spacer masks for etching a second level into the Si wafer have been defined. Following this, Si RIE is carried out and the remaining $\mathrm{SiO}_{2}$ mask is removed by standard buffered oxide wet etching. This process exposes the final structure illustrated in step 6 of Fig. 11. During the etch carried out in step 5, the exposed top level Si starts to etch unevenly leading to Si grass on the top level. This can be eliminated by using a hard mask (such as $\mathrm{SiO}_{2}$ ) on the starting Si sample. This hard mask enables a smooth top surface to be formed by protecting it when the second lower level Si etch is carried out. Fig. 13 shows the top and cross-section views of bilaterally symmetric multilevel grating structure with a smooth top Si surface, but has etch artifacts such as Si grass in the lowermost Si level which arise due to micromasking[47][50] during the second level etch. After the second level has been defined, the hard mask can be removed using standard buffered oxide wet etch.This step reveals the bilaterally symmetric multilevel structures as shown in Fig. 13. This demonstration was constrained to a small area and suffered from low-frequencyline edge roughness due to the use of suboptimal e-beam lithography for the initial patterning.The smallest structures in this demonstration are the paired grating structures with widths equal to $100 \mathrm{~nm}$. The critical alignment that was achieved using ALD in this demonstration is that of the two gratings to the trenches on either side: they are bothexactly the same distance away from the trenches on the respective sides due to the conformal nature of mask deposition.
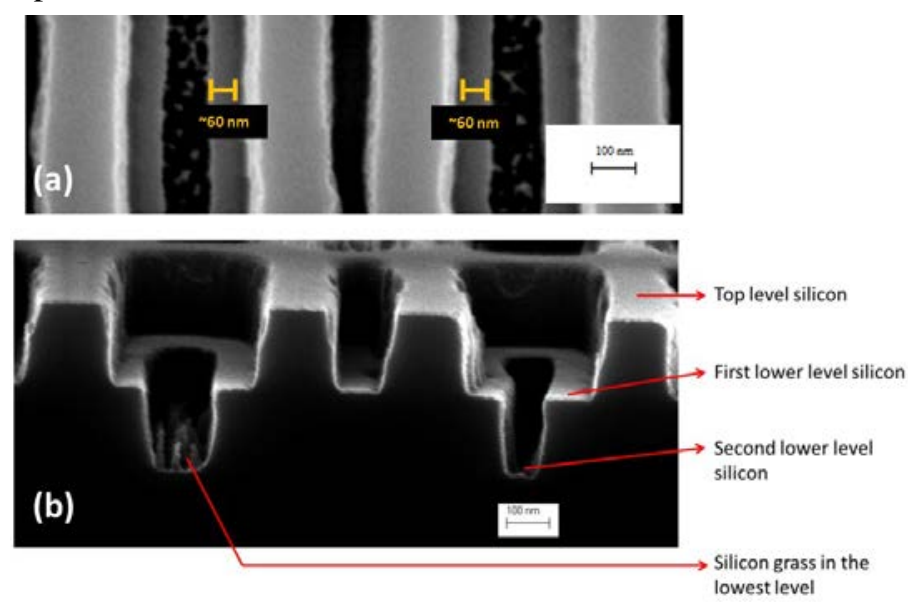

Fig. 13. Scanning electron micrograph showing bilaterally symmetric multilevel structures with smooth top level due to use of $\mathrm{SiO}_{2}$ hard mask, but $\mathrm{Si}$ grass in the lowermost level due to micromasking; (a) top view - SEM scale bar is $100 \mathrm{~nm}$; (b) cross-section view - SEM scale bar is $100 \mathrm{~nm}$.

\section{Self-Aligned Silicon Tubes}

The structure illustrated in Fig. 2 is a hollow Si tube. Such a structure has applications in nanophotonics and in nanoelectronics, specifically in super-capacitors, owing to its higher surface area per unit projected area compared to solid Si nanowire capacitors. An ALD based self-alignment process in which the outer and inner circles are perfectly concentric, is demonstrated here.The patterning technique used in this process to create the initial pattern of pillars in the resist is JFIL (Fig. 14). After RIE etching of the residual layer, the resist pillars thus formed are used as mandrel to allow conformal SiO2 spacer deposition with ALD, as shown in step (c) of Fig. 14. Blanket RIE of the $\mathrm{SiO}_{2}$ film is then carried out to expose the resist cores from the top (step (d) of Fig. 14), as shown in Fig. 15. 


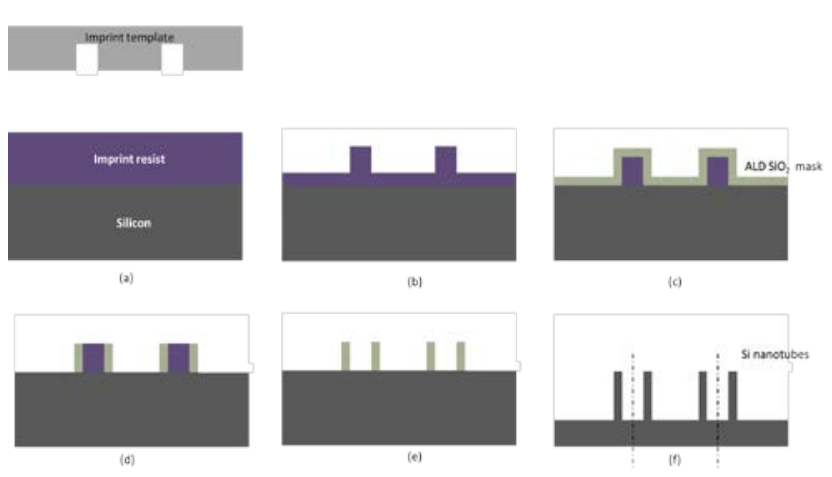

Fig. 14. Illustration (cross-section) of the process to fabricate Si tubes. (a) Imprint resist on Si substrate and shape of the nanoimprint template (b) Resist pillars patterned using J-FIL (c) Removal of residual layer followed by low temperature ALD of spacer material (d) Vertical etch of spacer material to define side wall spacers in the shape of a ring (e) Removal of resist core (f) RIE etch of using ring shaped spacer mask.

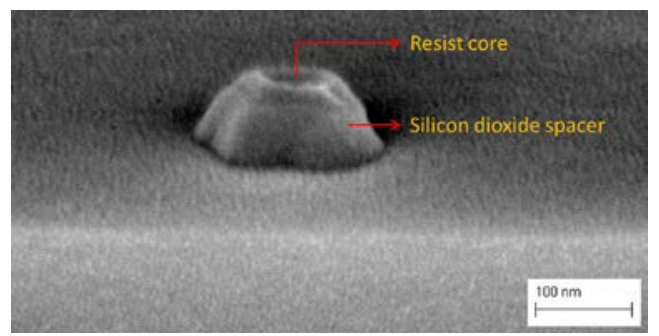

Fig. 15. Scanning electron micrograph showing patterned $\mathrm{SiO}_{2}$ spacer ring around the resist core. Scale bar is $100 \mathrm{~nm}$.

The exposed $\mathrm{Si}$ is then etched, thus forming a $\mathrm{Si}$ tube with the $\mathrm{SiO}_{2}$ mask on top, as shown in Fig. 16. After this etch, the remaining $\mathrm{SiO}_{2}$ mask is removed by wet etching, which then exposes the desired self-aligned tube structures in Si as illustrated by step (f) of Fig. 14 and shown in Fig. 17.The tubes demonstrated have an outer diameter equal to $180 \mathrm{~nm}$ and wall thickness equal to $23 \mathrm{~nm}$. The critical alignment enabled by ALD in this demonstration is manifested as uniform wall thickness around the circumference of the tubes. This ensures that the centers of the outer and inner cylinders of the tubes are perfectly aligned.

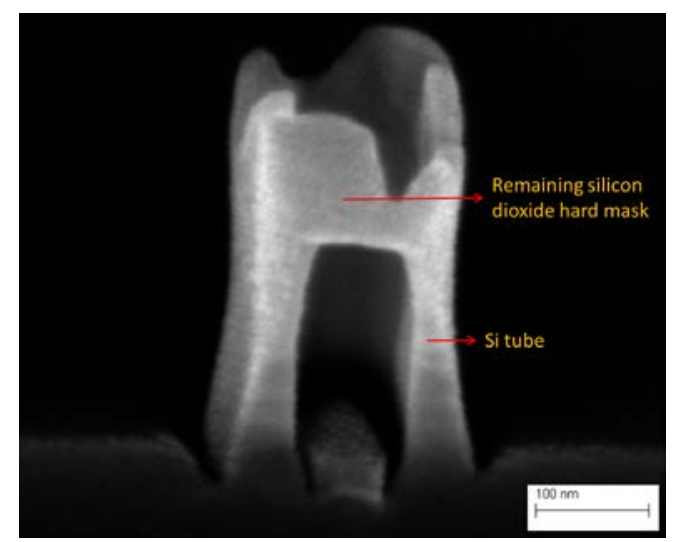

Fig. 16. Scanning electron micrograph (cut off - tilted view) showing etched $\mathrm{Si}$ tube and remaining $\mathrm{SiO}_{2}$ mask intact after sample cleaving. Scale bar is $100 \mathrm{~nm}$.
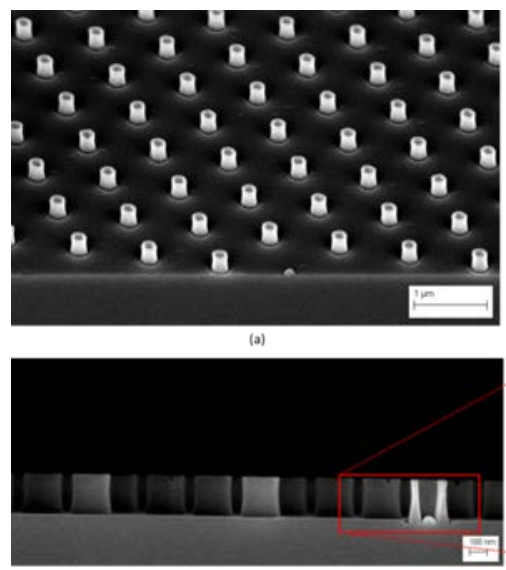

(c)
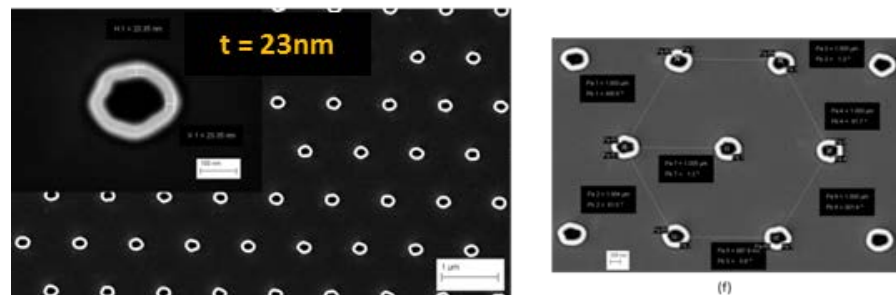

Fig. 17.Scanning electron micrographs corresponding to step (f) of Fig. 14. (a) Tilted view of Si tubes - scale bar is $1 \mu \mathrm{m}$; (b) Magnified tilted view of single Si tube structure - scale bar is $100 \mathrm{~nm}$; (c) Cross-sectional view of $\mathrm{Si}$ tubes - scale bar is $100 \mathrm{~nm}$; (d) Magnified cross sectional cut-off view of a single Si tube structure - scale bar is $100 \mathrm{~nm}$; (e) Top view of Si tubes - scale bar is $1 \mu$ mand (inset) magnified top-view of one Si tube - scale bar is $100 \mathrm{~nm}$. (f) Top view showing hexagonal tube arrangement due to the starting hexagonal pattern in the nanoimprint template- scale bar is $100 \mathrm{~nm}$.

\section{Asymmetric MultileVel StRUCtURES}

The structure illustrated in Fig. 3 is an asymmetric multilevel grating structure which has applications in nanophotonic devices such as metamaterial wire-grid polarizers (WGP).Most high-performance WGPs are fabricated by RIE of the polarizing metal such as Al. WGPs have also been previously demonstrated by shadowing angle deposition or glancing angle deposition (GLAD) of the polarizing metal[51]-[53], thus circumventing Al RIE, which is an expensive process. The process demonstrated here, thus follows the GLAD approach in order to remain cost-effective. While these GLAD WGPs have lower cost, they also suffer from lower performance than the etched WGPs. Hence, there is an established need to improve the performance of GLAD WGPs, while remaining cost-effective.Through FDTD performance evaluations coupled with genetic algorithm based geometric optimization[40], it can be observed that conventional single levelGLAD grating cross-sections are ineffective in providing high extinction ratios while maintaining high percentage transmission. On the other hand, certain asymmetric multilevel cross sections as shown in Fig. 18help improve the aspect ratio of the polarizing metal, a parameter that directly influences extinction ratio of the polarizer, without compromising the percentage transmission. They also improve the mechanical stability of the underlying gratings and offer intermediate structural support for metal deposition. A technique to fabricate asymmetric multilevel grating structures is described next (Fig. 19). The exact geometry and $\mathrm{CD}$ of various levels of the asymmetric 


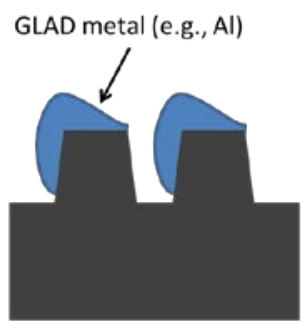

(a) (b)

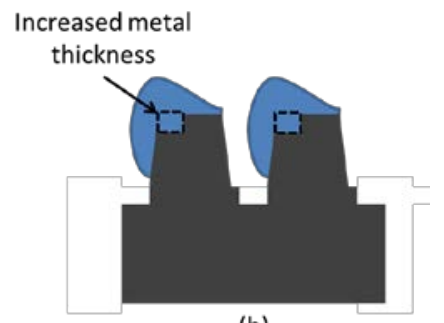

Fig. 18. Illustration of (a) single level WGP; (b) asymmetric multilevel WGP with improved polarizing metal aspect ratio

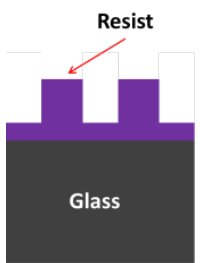

(1)

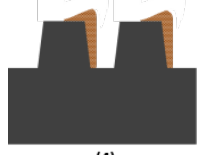

(4)

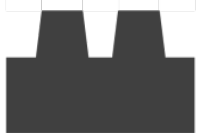

(2)

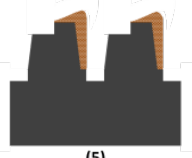

(5)
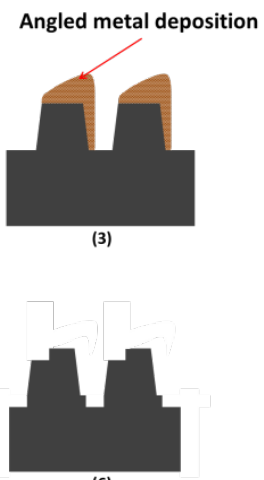

(6)
Fig. 19. Illustration of the process to fabricate asymmetric multilevel nanogratings. (1) Grating patterns on polymer resist patterned by J-FIL. (2) Residual layer etch followed by pattern transfer into fused silica substrate or $\mathrm{SiO}_{2}$ on Si substrate. (3) Removal of resist mask, followed by glancing angle deposition of metal mask. (4) Blanket etch of metal to define CD of metal mask. (5) RIE of $\mathrm{SiO}_{2}$ using metal mask. (6) Removal of metal mask by wet processing.

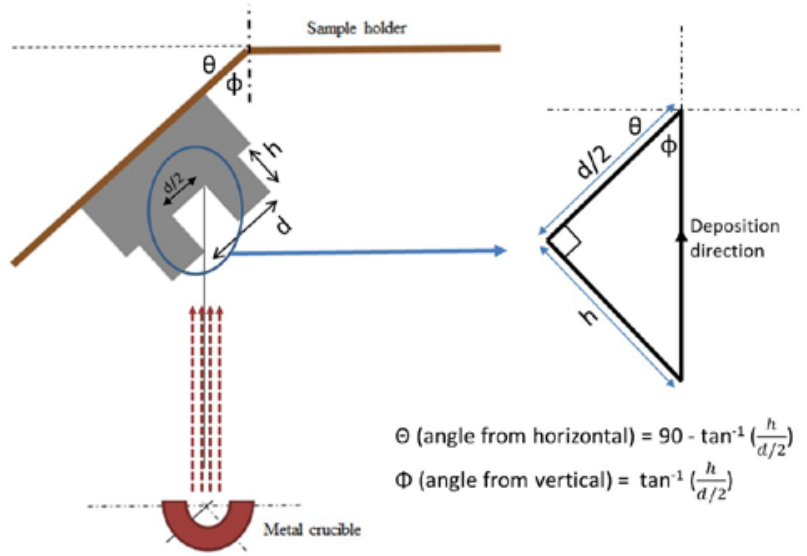

Fig. 20.Illustration of a tilted grating sample in an e-beam evaporator.

structures may vary based on optimal performance requirements from device characterization and simulation. This may in turn alter the unit process parameters in the fabrication process described next, but the basic process flow to fabricate such asymmetric multilevel structures remains the same. The goal of this demonstration is to validate this process flow for fabrication of asymmetric multilevel grating structures over large areas. J-FIL is used to define resist grating patterns on $\mathrm{SiO}_{2}$ that is thermally grown on $\mathrm{Si}$. This is followed by RIE of the residual resist layer, which is then used as a mask, to etch into $\mathrm{SiO}_{2}$ by RIE. After defining the features in $\mathrm{SiO}_{2}$, a piranha clean is used to remove the remaining resist mask. The next step is the glancing angle deposition (GLAD) using e-beam evaporation of a metal mask, which is necessary to define the asymmetric structure.

E-beam evaporation is a line of sight deposition process. When a substrate with grating patterns is tilted, the grating line structures shadow the deposition of metal on adjacent structures, leading to preferential deposition of metal on one side of a line feature.The substrate tilt angle depends on the half-pitch of the grating structures $d / 2$ (grating pitch = $d$ )and the height of the structures $h$. For instance, if $\theta$ is the angle at which the substrate is tilted from the horizontal as shown in Fig. 20, in order to deposit metal at a glancing angle on a substrate that has $65 \mathrm{~nm}$ half-pitch gratings with a height of $100 \mathrm{~nm}, d=130 \mathrm{~nm}, h=100 \mathrm{~nm}, \tan (90-\theta)=\mathrm{h} /(\mathrm{d} / 2)$ which approximates to a value of $33^{\circ}$ for $\theta$. Thus, for a sample with grating structures of aforementioned dimensions, the sample holder must be angled at least $\theta=33^{\circ}$ from the horizontal axis or at most $\varphi=57^{\circ}$ from the vertical axis. The range of angles for $\theta$ and $\varphi$ are as follows: $0^{\circ}<\varphi<\varphi_{\max }$, where $\varphi_{\max }$ is the value of $\varphi$ beyond which deposition starts to occur in the trenches; and $\theta_{\min }<\theta<90^{\circ}$, where $\theta_{\min }$ is the value of $\theta$ below which deposition occurs in the trenches.This approach has been previously demonstrated for the fabrication of wiregrid polarizers[51]-[54].Cr is chosen as the masking metal since it has good etch selectivity with $\mathrm{SiO}_{2}$. Once $\mathrm{Cr}$ is deposited at a glancing angle (SEM shown in Fig. 21), vertical RIE etch is carried out to define the CD of the etch mask.

Due to the angled profile of the mask (as seen in step 3 of Fig. 19), the mask exposes the underlying $\mathrm{SiO}_{2}$ on the left edge of the grating firstwhen vertical RIE of $\mathrm{Cr}$ is carried out. Based on the desired mask CD, a timed etch is then carried out to form the desired mask $\mathrm{CD}$ as shown in Fig. 22. Once the metal mask $\mathrm{CD}$ is defined, $\mathrm{SiO}_{2}$ etch is carried out to define the second $\mathrm{SiO}_{2}$ level as shown in step 5 of Fig. 19. The

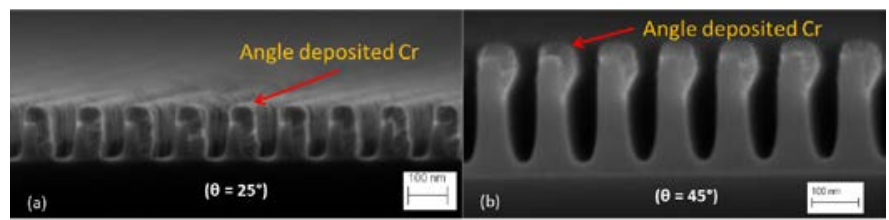

Fig. 21. Scanning electron micrograph (cross-section) of Cr mask e-beam evaporated using the glancing angle deposition technique; (a) $\theta=25^{\circ}$; (b) $\theta$ $=45^{\circ}$. SEM scale bar is $100 \mathrm{~nm}$ in both images.

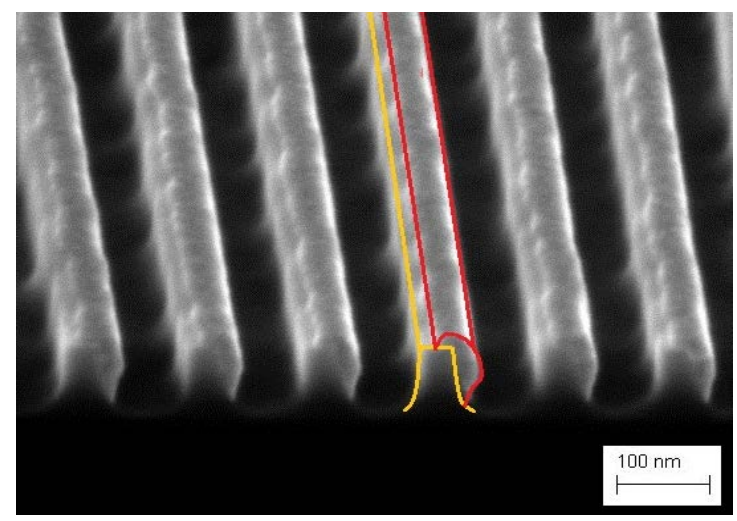

Fig. 22. Scanning electron micrograph of etched $\mathrm{Cr}$ angled mask. The region highlighted in red is the etched Cr mask and the region highlighted in yellow is the $\mathrm{SiO}_{2}$ grating. Scale bar is $100 \mathrm{~nm}$. 
remaining $\mathrm{Cr}$ mask is then removed by wet processing. At this point an asymmetric multilevel structure is defined as shown in step 6 of Fig. 19 as well as in Fig. 23, where the formed asymmetric multilevel nanostructures are shown. The width of the asymmetric level in this demonstration is $15 \mathrm{~nm}$. This dimension is dictated by the width of the remaining angled metal mask that can be precisely controlled by vertical RIE of the mask. In the proposed application, this width determines the mechanical support offered by the resist structure for angled metal packing, that influences metal aspect ratio in the WGP device.

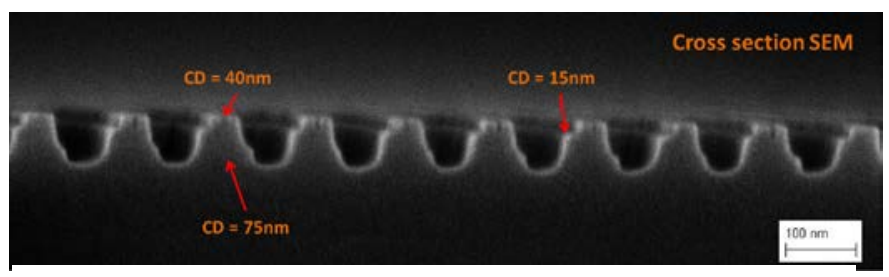

Fig. 23. Scanning electron micrograph (cross section) of asymmetric multilevelnanograting structures. SEM scale bar is $100 \mathrm{~nm}$.

\section{EXPERIMENTAL}

\section{A. Tools \\ 1) Patterning}

The initial nanoscale lithography for the symmetric, hollow tubular, and asymmetric multilevel structures was performed in the Imprio ${ }^{\circledR}{ }^{1}$ TR1100 J-FIL tool from Molecular Imprints Inc. The alignment capability of this tool is approximately $10 \mu \mathrm{m}$ and hence, this tool cannot be used for nanoscale overlay directly. For the bilaterally symmetric structures, electron beam lithography was performed on the JEOLJBX6000FS system.

\section{2) Etching}

Residual resist layer removal, $\mathrm{Cr}$ dry etch, and certain $\mathrm{SiO}_{2}$ dry etch processes were performed in the Oracle etcher (bottom electrode diameter $=200 \mathrm{~mm}$ ) available from Trion Technology. Certain other $\mathrm{SiO}_{2}$ dry etch processes and Si dry etch processes were performed in the 790 RIE etcher from Plasma Therm (bottom electrode diameter $=200 \mathrm{~mm}$ ). TiN dry etch was carried out in the Plasma Lab 100 RIE-ICP tool from Oxford Instruments (bottom electrode diameter $=205$ $\mathrm{mm})$.

\section{3) Deposition}

Atomic layer deposition of $\mathrm{TiN}$ and $\mathrm{SiO}_{2}$ was performed in the Fiji ALD tool from Cambridge Nanotech. E-beam evaporation of $\mathrm{Cr}$ was done in the SEC-600/SE-600 high vacuum deposition system from CHA Industries. Plasma enhanced chemical vapor deposition of $\mathrm{SiO}_{2}$ was performed in the 790 RIE system from Plasma Therm. Au/Pdwas sputter coated on SEM samples using the Emitech K575X sputter coater from Quorum Technologies.

\footnotetext{
${ }^{1}$ Monomat, Imprio, and Transpin are registered trademarks of Molecular Imprints, Inc., Austin, TX.
}

\section{4) Metrology}

Scanning electron micrographs were obtained using the Zeiss Neon 40 SEM. Film thickness measurements were performed using the M-2000 Ellipsometer from J.A. Woollam Co., Inc.

\section{B. Materials}

The nanoimprint resist is a proprietary formulation called Monomat NS-A-M ${ }^{1}$,commercially available from Molecular Imprints Inc. (MII). An adhesion promoter called Transpin ${ }^{1}$, also commercially available from MIIensures that imprinted resist adheres to the wafer and does not peel away with the template during the separation stage of the imprint process. The resist used in the e-beam lithography process is ZEP520A available from Zeon Corporation. Ti precursor used in the ALD of TiN is tetrakis (dimethlyamido) titanium IV sourced from Sigma-Aldrich. Si precursor used in the ALD of $\mathrm{SiO}_{2}$ is tris(dimethylamino)silane commonly referred to as TDMAS sourced from Sigma-Aldrich.

\section{Process Details}

\section{1) Self-Aligned Symmetric Multilevel Structures}

J-FIL is used for patterning grating features with CD $=65$ $\mathrm{nm}$, pitch $=130 \mathrm{~nm}$, and feature depth $=100 \mathrm{~nm}$ over a circular area of diameter $=80 \mathrm{~mm}$. The residual layer formed after imprinting is removed using the process conditions: $\mathrm{O}_{2}$ flow rate $=2 \mathrm{sccm}$, Ar flow rate $=70$ sccm, Etch chamber pressure $=15 \mathrm{mT}$, RIE RF Power $=65 \mathrm{~W}$, Reflected RF Power $=4 \mathrm{~W}$, Etch rate $=0.8 \mathrm{~nm} / \mathrm{s}$. Etching of $\mathrm{SiO}_{2}$ using imprint resist mask is carried out using the following process: $\mathrm{CHF}_{3}$ flow rate $=15 \mathrm{sccm}$, Ar flow rate $=50 \mathrm{sccm}, \mathrm{CF}_{4}$ flow rate $=$ 5sccm, chamber pressure $=115 \mathrm{mTorr}$, RIE $\mathrm{P}=125 \mathrm{~W}$, Reflected RF P $=7 \mathrm{~W}$, Etch rate $=0.2 \mathrm{~nm} / \mathrm{s}$. The selectivity of the resist mask to thermal oxide is $\sim 3$ for the aforementioned etch recipe. ALD of $\mathrm{TiN}$ is carried out using tetrakis (dimethylamido) titanium IV as the $\mathrm{Ti}$ precursor. The $\mathrm{Ti}$ precursor is pulsed for $0.2 \mathrm{~s}$ and is alternated with $\mathrm{NH}_{3}(50$ sccm flow for $6 \mathrm{~s}$ ) while the chamber and sample are maintained at $250^{\circ} \mathrm{C}$ to form a conformal layer of TiN on the etched $\mathrm{SiO}_{2}$. Etching of TiN to define sidewall spacers is done using the following process: $\mathrm{Cl}_{2}$ flow rate $=7.5 \mathrm{sccm}$, Ar flow rate $=20 \mathrm{sccm}$, chamber pressure $=5 \mathrm{mT}$, RIE P $=100 \mathrm{~W}$, ICP $\mathrm{P}=900 \mathrm{~W}$, Etch rate $=0.37 \mathrm{~nm} / \mathrm{s}$. Etching of $\mathrm{SiO}_{2}$ using $\mathrm{TiN}$ mask is carried out using the following process: $\mathrm{CHF}_{3}$ flow rate $=40 \mathrm{sccm}, \mathrm{O} 2$ flow rate $=2 \mathrm{sccm}$, chamber pressure $=$ 40mTorr, RF P $=400 \mathrm{~W}$, Etch rate $=1 \mathrm{~nm} / \mathrm{s}$.

\section{2) Bilaterally Symmetric Multilevel Structures}

The patterning process used is e-beam lithography with dose $=90 \mu \mathrm{C} / \mathrm{cm}^{2}$ and beam current $=100 \mathrm{pA}$. A positive tone e-beam resist is spin coated onto a Si sample at 4500rpm for 60s. This approximates to a resist thickness of around $400 \mathrm{~nm}$. A post bake is carried out at $180^{\circ} \mathrm{C}$ for 120 s. The resist is developed in n-amyl acetate for 120s followed by rinsing the sample with isopropyl alcohol (IPA). Pattern transfer by RIE into Si using the resist mask is carried out using the following etch: 1) high power etch: $\mathrm{Cl}_{2}$ flow rate $=4 \mathrm{sccm}$, $\mathrm{HBr}$ flow rate $=25.4 \mathrm{sccm}, \mathrm{P}=400 \mathrm{~W}$, chamber pressure $=28 \mathrm{mTorr}$, etch 
time $=1$ minute; 2) low power etch: $\mathrm{Cl}_{2}$ flow rate $=4 \mathrm{sccm}$, $\mathrm{HBr}$ flow rate $=25.4 \mathrm{sccm}, \mathrm{P}=275 \mathrm{~W}$, chamber pressure $=$ $28 \mathrm{mTorr}$, Etch rate $=1.2 \mathrm{~nm} / \mathrm{s}$. The Si containing precursor gas used for ALD of $\mathrm{SiO}_{2}$ is TDMAS. By alternating TDMAS (0.4 s pulse) with $\mathrm{O}_{2}$ (50 sccm for $3 \mathrm{~s}$ ) and striking a plasma (300 W for $10 \mathrm{~s}$ ) in the ALD chamber maintained at $110^{\circ} \mathrm{C}$, a conformal layer of $\mathrm{SiO}_{2}$ is formed on the $\mathrm{Si}$ gratings at the rate $0.72 \AA /$ cycle. Etching of $\mathrm{SiO}_{2}$ to form sidewall spacers is carried out using: $\mathrm{CHF}_{3}$ flow rate $=15 \mathrm{sccm}$, Ar flow rate $=$ 50 sccm, $\mathrm{CF}_{4}$ flow rate $=5 \mathrm{sccm}$, chamber pressure $=$ $115 \mathrm{mTorr}$, RIE $\mathrm{P}=125 \mathrm{~W}$, Reflected RF $\mathrm{P}=7 \mathrm{~W}$, Etch rate $=$ $0.2 \mathrm{~nm} / \mathrm{s}$. Etching of $\mathrm{Si}$ using $\mathrm{SiO}_{2}$ spacer mask is carried out using $\mathrm{HBr} / \mathrm{Cl}_{2}$ etch chemistry mentioned previously in this section. The remaining $\mathrm{SiO}_{2}$ mask can be removed by wet etching using buffered oxide etchants.

\section{3) Self-Aligned Si Tubes}

J-FIL is used for patterning resist pillars distributed in a hexagonal arrangement with $C D=180 \mathrm{~nm}$, pitch $=1 \mu \mathrm{m}$, and feature depth $=100 \mathrm{~nm}$ over a circular area of diameter $=$ $80 \mathrm{~mm}$. The residual layer formed after imprinting is removed using the following etch: $\mathrm{O}_{2}$ flow rate $=2 \mathrm{sccm}$, Ar flow rate $=$ 70sccm, Etch chamber pressure $=15 \mathrm{mT}$, RIE RF Power $=$ $65 \mathrm{~W}$, Reflected RF Power $=4 \mathrm{~W}$, Etch rate $=0.8 \mathrm{~nm} / \mathrm{s}$. ALD of $\mathrm{SiO}_{2}$ on resist pillars is carried out by alternating TDMAS (0.4 s pulse) with $\mathrm{O}_{2}$ (50 sccm for $3 \mathrm{~s}$ ) and striking a plasma (300 W for $10 \mathrm{~s}$ ) in the ALD chamber maintained at $110^{\circ} \mathrm{C}$. Blanket etching of the thin $\mathrm{SiO}_{2}$ film is then carried out using the following process conditions: $\mathrm{CHF}_{3}$ flow rate $=15 \mathrm{sccm}$, Ar flow rate $=50 \mathrm{sccm}, \mathrm{CF}_{4}$ flow rate $=5 \mathrm{sccm}$, chamber pressure $=115 \mathrm{mTorr}$, RIE $\mathrm{P}=125 \mathrm{~W}$, Reflected RF $\mathrm{P}=7 \mathrm{~W}$, Etch rate $=0.2 \mathrm{~nm} / \mathrm{s}$. Etching of Si tubes using ring shaped $\mathrm{SiO}_{2}$ mask is carried out using the following etch conditions: 1) high power etch: $\mathrm{Cl}_{2}$ flow rate $=4 \mathrm{sccm}, \mathrm{HBr}$ flow rate $=$ $25.4 \mathrm{sccm}, \mathrm{P}=400 \mathrm{~W}$, chamber pressure $=28 \mathrm{mTorr}$, etch time = 1 minute; 2) low power etch: $\mathrm{Cl}_{2}$ flow rate $=4 \mathrm{sccm}, \mathrm{HBr}$ flow rate $=25.4 \mathrm{sccm}, \mathrm{P}=275 \mathrm{~W}$, chamber pressure $=28 \mathrm{mTorr}$, Etch rate $=1.2 \mathrm{~nm} / \mathrm{s}$. The remaining $\mathrm{SiO}_{2}$ mask is removed by wet etching using buffered oxide etchants.

\section{4) Asymmetric Multilevel Structures}

J-FIL is used for patterning grating features with CD $=65$ $\mathrm{nm}$, pitch $=130 \mathrm{~nm}$, and feature depth $=100 \mathrm{~nm}$ over a circular area of diameter $=80 \mathrm{~mm}$. The residual layer formed after imprinting is removed using the following etch: $\mathrm{O}_{2}$ flow rate $=2 \mathrm{sccm}$, Ar flow rate $=70 \mathrm{sccm}$, Etch chamber pressure $=$ 15mT, RIE RF Power $=65 \mathrm{~W}$, Reflected RF Power $=4 \mathrm{~W}$, Etch rate $=0.8 \mathrm{~nm} / \mathrm{s}$. Etching of $\mathrm{SiO}_{2}$ using imprint resist mask is carried out in the following etch conditions: $\mathrm{CHF}_{3}$ flow rate $=15 \mathrm{sccm}$, Ar flow rate $=50 \mathrm{sccm}, \mathrm{CF}_{4}$ flow rate $=$ 5sccm, chamber pressure $=115 \mathrm{mT}$ Torr, RIE $\mathrm{P}=125 \mathrm{~W}$, Reflected RF $\mathrm{P}=7 \mathrm{~W}$, Etch rate $=0.2 \mathrm{~nm} / \mathrm{s}$. Deposition pressure for glancing angle deposition of Cr mask by e-beam evaporation is $5 \times 10^{-6}$ Torr. RIE of Cr mask to define mask $\mathrm{CD}$ is carried out in the following etch conditions: $\mathrm{Cl}_{2}$ flow rate $=40 \mathrm{sccm} ; \mathrm{O}_{2}$ flow rate $=10 \mathrm{sccm}$; $\mathrm{RIE} \mathrm{P}=80 \mathrm{~W}$; reflected RIE P $=1 \mathrm{~W}$; chamber pressure $=30 \mathrm{mTorr}$, Etch rate $=0.42$ $\mathrm{nm} / \mathrm{s}$. Etching $\mathrm{SiO}_{2}$ gratings using $\mathrm{Cr}$ as etch mask is done using: $\mathrm{CHF}_{3}$ flow rate $=15 \mathrm{sccm}$, Ar flow rate $=50 \mathrm{sccm}$,
$\mathrm{CF}_{4}$ flow rate $=5 \mathrm{sccm}$, chamber pressure $=115 \mathrm{mTorr}$, RIE $\mathrm{P}=$ $125 \mathrm{~W}$, Reflected RF P $=7 \mathrm{~W}$, Etch rate $=0.2 \mathrm{~nm} / \mathrm{s}$.

\section{CONCLUSION}

There is a need for fabrication of multilevel nanostructures with precise alignment and complex 3D geometries for a variety of applications in areas such as nanoscale electronics and photonics. This places stringent demands on nanoscale overlay requirements for state-of-theart lithography processes. This is exacerbated when patterning flexible substrates or over large areas on rigid substrates. In this paper, a solution for overcoming these challenges has been demonstrated using the concept of self-aligned multilevel nanoimprint templates (SAMT) for multilevel nanoimprint lithography. SAMTs are fabricated using a combination of nanoscale lithography (e.g., nanoimprint lithography and electron beam lithography), precise spacers using ALD, and choice of appropriate etch mask materials. This has enabled the demonstration of four self-aligned multilevel fabrication processes: symmetric multilevel self-aligned $\mathrm{SiO}_{2}$ nanoscale grating structures on $\mathrm{Si}$ enabled by ALD of TiN spacer material; bilaterally symmetric multilevel Si nanoscale grating structures enabled by ALD of $\mathrm{SiO}_{2}$ spacer material; selfaligned $\mathrm{Si}$ tube structures with nanoscale dimensions enabled by low temperature ALD of $\mathrm{SiO}_{2}$ spacer material on cured resist polymer; and asymmetric multilevel precisely aligned $\mathrm{SiO}_{2}$ nanoscale grating structures on $\mathrm{Si}$ enabled by glancing angle deposition (GLAD) of $\mathrm{Cr}$ hard mask. These processes demonstrate the versatility of starting with single-level patterns and using ALD and selective RIE to obtain large area patterns with various classes of multilevel nanostructures. Exemplar applications such as self-aligned NMOS transistor array, nanotube ultra-capacitors, and metamaterial GLAD wire-grid polarizers have been identified for these multilevel nanostructures.

\section{APPENDIX A}

\section{FABrication Of A WAFER-SCALE NMOS ArRAy Using A} SINGLE NANOIMPRINT LITHOGRAPHY STEP

An illustration of the method to be described is shown in Fig. A1. The material stack for this method, in one instance may comprise a p-type Si substrate (20), thin high-k dielectric gate oxide layer (30), hard mask material 1 (40) which may be a nitride or an oxide, hard mask material 2 (50) which may be an oxide or a nitride (different from hard mask material 1), and polymer sacrificial resist (60). The multilevel imprint template (10) is applied onto the polymer resist. When the template (10) is removed after the resist is cured, it forms a negative multi-tier structure (61) as shown in step 2. Residual resist layer is removed by RIE as shown in step 3. Matched etching by RIE can then be carried out to transfer the resist pattern (61) onto the two underlying hard mask layers (50 and 40). The first two levels from top in the patterned resist (61) are transferred onto layer 50 (and now become 51) and the third level from 61 is transferred onto 40 (and now becomes 41). This matched etching can be carried out by alternately etching the resist (61) and hard masks (50 and 40) transferring one feature layer at a time. The result of this etch is shown 


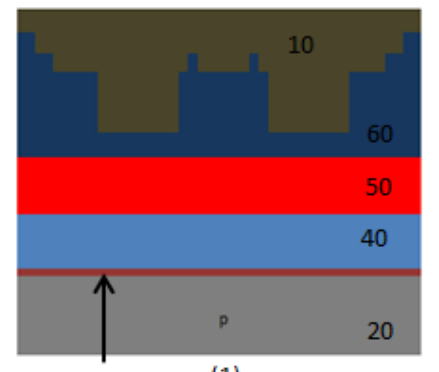

(1)

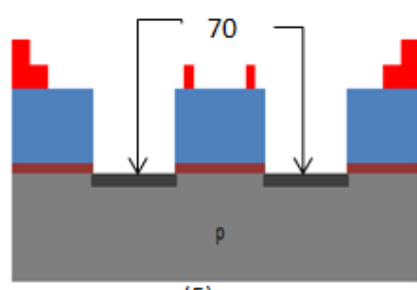

(5)

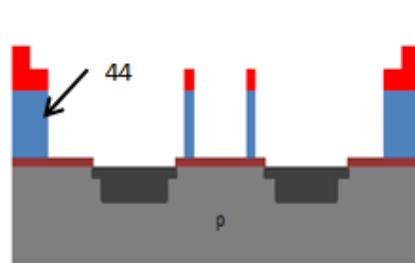

(9)

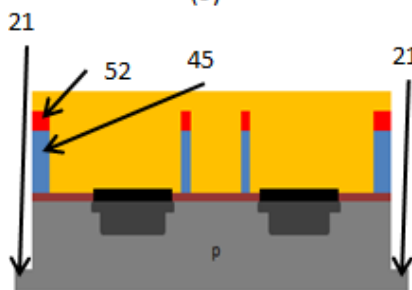

(13)

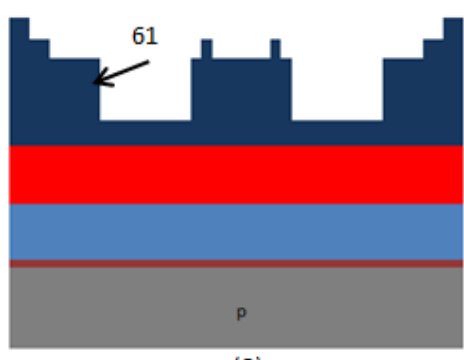

(2)

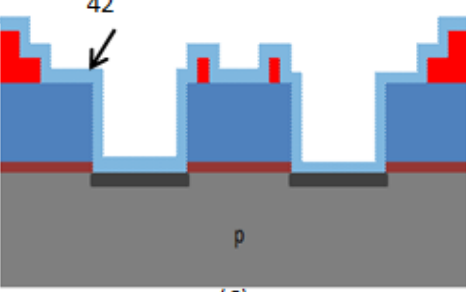

(6)

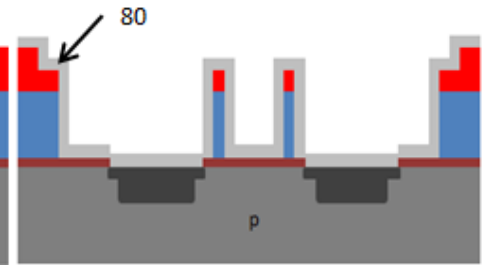

(10)

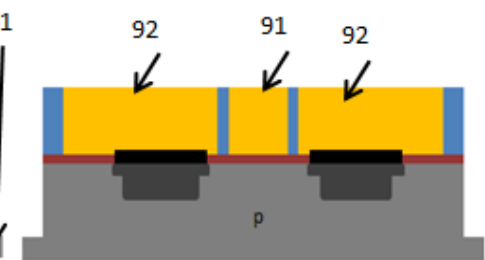

(14)

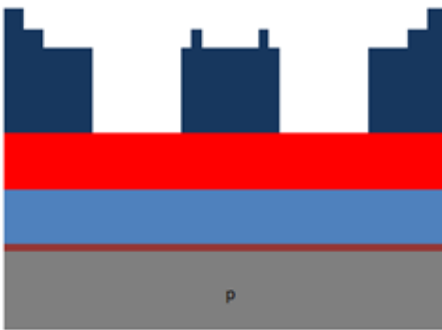

(3)

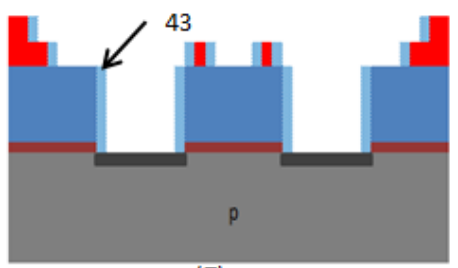

(7)

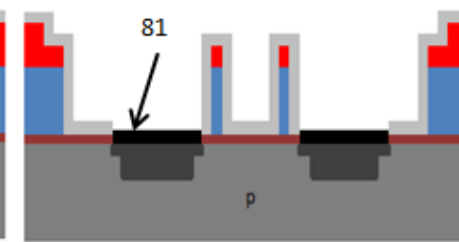

(11)

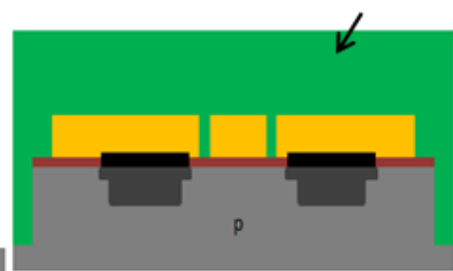

(15)

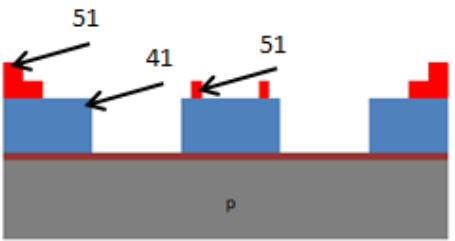

(4)

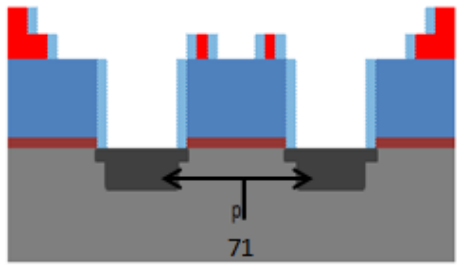

(8)

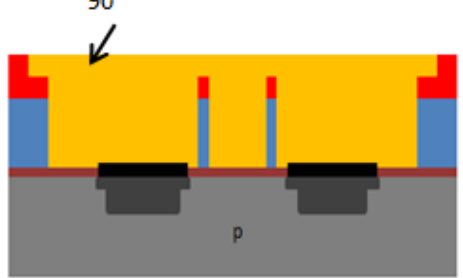

(12)

Fig. A1. Illustration of method to fabricate wafer-scale NMOS array [40]

instep 4. Using hard mask 1 (41) as implant mask, low energy ion implantation is carried out to form shallow lightly doped source and drain regions (70) in the exposed substrate (20). In step 6, a thin layer of material (42) same as that of hard mask material 1 (40) is deposited. This material is then blanket etched to define side wall spacers (43) in step 7. These side wall spacers (43), along with the pre-existing hard mask material (41) serve as implant masks for high energy doping of exposed substrate (20) to form deeper highly n-doped source and drain regions (71) in step 8.Using hard mask material 2 (51) as etch mask, hard mask material 1 (41 and 43 are the same material) is etched and removed in step 9. In step 10 , a thin transition metal layer (80) is blanket deposited. In one instance this metal layer could be Titanium. On slight heating, this transition metal layer (80) reacts with the exposed doped silicon regions (70) to form transition metal silicide (81) which is a low resistance contact as shown in step 11. The transition metal layer (80) does not react with the exposed hard mask layers (51 and 44) and reacts only with exposed silicon (70), thus forming a self-aligned metal silicide or salicide (81). Step 12 is the result of two sub-steps: the unreacted transition metal is etched away by a piranha clean or suitable dry etch; and gate metal (90) is blanket deposited and planarized by CMP until remaining hard mask 2 (51) is exposed. After step 12, using the gate metal (90) as etch mask, exposed hard masks (51 and 44) are etched (in that order) and the remaining hard mask 2 becomes 52 and hard mask 1 becomes 45. Continuing to use the gate metal (90) as etch mask, RIE is done into exposed silicon to form isolation trenches (21) in step 13. In step 14, CMP of the gate metal (90) is carried out to expose hard mask 2 (52), which is then etched away using the gate metal (90) as mask. After step 14, continuing with the gate metal as etch mask, hard mask 1 (45) is also etched using RIE to expose gate oxide (30). This would also define the dimensions of the final gate (91) and S/D contacts (92). Field isolation oxide (100) is then blanket deposited in step 15. In the final step, the field oxide (100) is planarized using CMP to expose metal contacts (91 and 92), thus forming a self-aligned NMOS MOSFET with lightly doped source and drain regions suitable for short-channel devices.

\section{ACKNOWLEDGMENT}

This work was supported in part by the National Science Foundation Nanosystems Engineering Research Center on 
Nanomanufacturing Systems for Mobile Computing and Mobile Energy Technologies (NASCENT), NSF EEC Grant No. 1160494 and in part by the National Science Foundation Scalable Nanomanufacturing Program, NSF Contract No. ECCS-1120823. P. Joseph thanks Dr. V. Singh of Molecular Imprints Inc. for his support with etching. The author acknowledges the use of the NNIN facility at the Microelectronics Research Center, JJ Pickle Research Campus, UT-Austin, Austin TX.

\section{REFERENCES}

[1] B. D. Gates, Q. Xu, M. Stewart, D. Ryan, C. G. Willson, and G. M. Whitesides, "New approaches to nanofabrication: molding, printing, and other techniques," Chem. Rev., vol. 105, no. 4, pp. 11711196, Apr. 2005.

[2] “Intel® 14 nm Technology,” Intel. [Online]. Available: http://www.intel.com/content/www/us/en/siliconinnovations/intel-14nm-technology.html

[3] H. J. Levinson, “The lithographer's dilemma: shrinking without breaking the bank," in 29th European Mask and Lithography Conference, 2013, pp. 888602-888602.

[4] L. Lattard, M. McCallum, R. Morton, T. Fujiwara, K. Makino, A. Tokui, N. Takahashi, and S. Sasamoto, "Spacer process and alignment assessment for SADP process," in SPIE Advanced Lithography, 2012, pp. 832604-832604.

[5] R. Ruiz, H. Kang, F. A. Detcheverry, E. Dobisz, D. S. Kercher, T. R. Albrecht, J. J. de Pablo, and P. F. Nealey, "Density Multiplication and Improved Lithography by Directed Block Copolymer Assembly,” Science, vol. 321, no. 5891, pp. 936-939, Aug. 2008.

[6] C. A. Ross, Y. S. Jung, V. P. Chuang, F. Ilievski, J. K. W. Yang, I. Bita, E. L. Thomas, H. I. Smith, K. K. Berggren, G. J. Vancso, and J. Y. Cheng, "Si-containing block copolymers for self-assembled nanolithography," Journal of Vacuum Science \& Technology B, vol. 26, no. 6, pp. 2489-2494, Nov. 2008.

[7] J. G. Son, J.-B. Chang, K. K. Berggren, and C. A. Ross, "Assembly of Sub-10-nm Block Copolymer Patterns with Mixed Morphology and Period Using Electron Irradiation and Solvent Annealing," Nano Lett., vol. 11, no. 11, pp. 5079-5084, Nov. 2011.

[8] C. Chi, C.-C. Liu, L. Meli, K. Schmidt, Y. Xu, E. A. de Silva, M. I. Sanchez, R. A. Farrell, H. Cottle, D. Kawamura, L. Singh, T. Furukawa, K. Lai, J. W. Pitera, D. P. Sanders, D. R. Hetzer, A. W. Metz, N. M. Felix, J. C. Arnold, and M. E. Colburn, "DSA via hole shrink for advanced node applications," Proc. SPIE 9777, Alternative Lithographic Technologies VIII, 97770L (April 4, 2016); doi:10.1117/12.2219706.

[9] C.-C. C. Liu, E. Franke, F. L. Lie, S. Sieg, H. Tsai, K. Lai, H. Truong, R. Farrell, M. Somervell, D. Sanders, N. Felix, M. Guillorn, S. Burns, D. Hetzer, A. Ko, J. Arnold, and M. Colburn, "DSA patterning options for FinFET formation at $7 \mathrm{~nm}$ node," Proc. SPIE 9777, Alternative Lithographic Technologies VIII, 97770R (March 22, 2016); doi:10.1117/12.2219670.
[10] K. Schmidt, H. Osaki, K. Nishino, M. Sanchez, C.-C. Liu, T. Furukawa, C. Chi, N. M. Felix, and D. Sanders, "Strategies to enable directed self-assembly contact hole shrink for tight pitches,” Proc. SPIE 9777, Alternative Lithographic Technologies VIII, 97771U (1 April 2016); doi: 10.1117/12.2219213.

[11] M. A. McCord, P. Petric, U. Ummethala, A. Carroll, S. Kojima, L. Grella, S. Shriyan, C. T. Rettner, and C. F. Bevis, "REBL: design progress toward $16 \mathrm{~nm}$ half-pitch maskless projection electron beam lithography," in SPIE Advanced Lithography, 2012, pp. 832311832311.

[12] O. Wood, J. Arnold, T. Brunner, M. Burkhardt, J. H.-C. Chen, D. Civay, S. S.-C. Fan, E. Gallagher, S. Halle, M. He, C. Higgins, H. Kato, J. Kye, C.-S. Koay, G. Landie, P. Leung, G. McIntyre, S. Nagai, K. Petrillo, S. Raghunathan, R. Schlief, L. Sun, A. Wagner, T. Wallow, Y. Yin, X. Zhu, M. Colburn, D. Corliss, and C. Smolinski, "Insertion strategy for EUV lithography," presented at the Extreme Ultraviolet (EUV) Lithography III, 2012, vol. 8322, p. 832203.

[13] N. Felix, D. Corliss, K. Petrillo, N. Saulnier, Y. Xu, L. Meli, H. Tang, A. De Silva, B. Hamieh, M. Burkhardt, Y. Mignot, R. Johnson, C. Robinson, M. Breton, I. Seshadri, D. Dunn, S. Sieg, E. Miller, G. Beique, A. Labonte, L. Sun, G. Han, E. Verduijn, E. Han, B. C. Kim, J. Kim, K. Hontake, L. Huli, C. Lemley, D. Hetzer, S. Kawakami, and K. Matsunaga, "EUV patterning successes and frontiers,” Proc. SPIE 9776, Extreme Ultraviolet (EUV) Lithography VII, 977610 (March 18, 2016); doi:10.1117/12.2219894.

[14] B. Turkot, S. L. Carson, A. Lio, T. Liang, M. Phillips, B. McCool, E. Stenehjem, T. Crimmins, G. Zhang, and S. Sivakumar, "EUV progress toward HVM readiness,"Proc. SPIE 9776, Extreme Ultraviolet (EUV) Lithography VII, 977602 (March 18, 2016); doi:10.1117/12.2225014.

[15] H. J. Kwon, J. Harris-Jones, A. Cordes, M. Satake, Y. Li, I. Mochi, and K. A. Goldberg, "EUV mask multilayer defects and their printability under different multilayer deposition conditions," in SPIE Advanced Lithography, 2012, pp. 832209-832209.

[16] R. A. Vega and T. J. K. Liu, "Three-Dimensional FinFET Source/Drain and Contact Design Optimization Study," IEEE Transactions on Electron Devices, vol. 56, no. 7, pp. 1483-1492, Jul. 2009.

[17] S. Inaba, K. Okano, T. Izumida, A. Kaneko, H. Kawasaki, A. Yagishita, T. Kanemura, T. Ishida, N. Aoki, K. Ishimaru, K. Suguro, K. Eguchi, Y. Tsunashima, Y. Toyoshima, and H. Ishiuchi, "FinFET: the prospective multi-gate device for future SoC applications," in 2006 European Solid-State Device Research Conference, 2006, pp. 49-52.

[18] M. Bohr and K. Mistry, "Intel's revolutionary 22 nm transistor technology,” Intel website, 2011.

[19] S. Takahashi, K. Suzuki, M. Okano, M. Imada, T. Nakamori, Y. Ota, K. Ishizaki, and S. Noda, "Direct creation of three-dimensional photonic crystals by a topdown approach,” Nat Mater, vol. 8, no. 9, pp. 721-725, Sep. 2009. 
[20] S. Y. Chou and P. R. Krauss, "Imprint lithography with sub-10 nm feature size and high throughput," Microelectronic Engineering, vol. 35, no. 1-4, pp. 237240, Feb. 1997.

[21] M. Colburn, S. C. Johnson, M. D. Stewart, S. Damle, T. C. Bailey, B. Choi, M. Wedlake, T. B. Michaelson, S. V. Sreenivasan, J. G. Ekerdt, and C. G. Willson, “Step and flash imprint lithography: a new approach to highresolution patterning," in Emerging Lithographic Technologies III, Santa Clara, CA, USA, 1999, vol. 3676, pp. 379-389.

[22] T. Higashiki, T. Nakasugi, and I. Yoneda, "Nanoimprint lithography for semiconductor devices and future patterning innovation," in SPIE Advanced Lithography, 2011, pp. 797003-797003.

[23] S. V. Sreenivasan, "Nanoscale Manufacturing Enabled by Imprint Lithography,” MRS Bulletin, vol. 33, no. 09, pp. 854-863, Sep. 2008.

[24] S. V. Sreenivasan, B. J. Choi, P. D. Schumaker, and F. $\mathrm{Xu}$, "Status Of UV Imprint Lithography For Nanoscale Manufacturing," in Comprehensive Nanoscience And Technology, vol. 4, Oxford Academic Press, 2011, pp. 83-116.

[25] C. P. Taussig, P. Mei, and H.-J. Kim, "Method of forming at least one thin film device,” US7202179 B2, 10-Apr-2007.

[26] E. Lausecker, Y. Huang, T. Fromherz, J. C. Sturm, and S. Wagner, "Self-aligned imprint lithography for topgate amorphous silicon thin-film transistor fabrication," Applied Physics Letters, vol. 96, no. 26, p. 263501, Jun. 2010.

[27] B. H. Chao, F. Palmieri, W.-L. Jen, D. H. McMichael, C. G. Willson, J. Owens, R. Berger, K. Sotoodeh, B. Wilks, J. Pham, and others, "Dual damascene BEOL processing using multilevel step and flash imprint lithography," in SPIE Advanced Lithography, 2008, p. 69210C-69210C.

[28] S. MacDonald, G. Hughes, M. Stewart, F. Palmieri, and C. G. Willson, "Design and fabrication of highly complex topographic nano-imprint template for dual Damascene full 3-D imprinting,” Proc. SPIE 5992, 25th Annual BACUS Symposium on Photomask Technology, 59922F (8 November 2005); doi: 10.1117/12.632312.

[29] A. Cherala, P. Schumaker, B. Mokaberi, K. Selinidis, B. J. Choi, M. J. Meissl, N. N. Khusnatdinov, D. LaBrake, and S. V. Sreenivasan, "Nanoscale Magnification and Shape Control System for Precision Overlay in Jet and Flash Imprint Lithography," IEEE/ASME Transactions on Mechatronics, vol. 20, no. 1, pp. 122-132, Feb. 2015.

[30] D. Lentz, G. Doyle, M. Miller, G. Schmidt, M. Ganapathisuramanian, X. Lu, D. Resnick, and D. L. LaBrake, "Whole wafer imprint patterning using step and flash imprint lithography: a manufacturing solution for sub-100-nm patterning," Proc. SPIE 6517, Emerging Lithographic Technologies XI, 65172F (16 March 2007); doi: 10.1117/12.720671.
[31] M. M. Alkaisi, W. Jayatissa, and M. Konijn, "Multilevel nanoimprint lithography," Current Applied Physics, vol. 4, no. 2-4, pp. 111-114, Apr. 2004.

[32] A. Schleunitz and H. Schift, "Fabrication of 3D patterns with vertical and sloped sidewalls by grayscale electronbeam lithography and thermal annealing," Microelectronic Engineering, vol. 88, no. 8, pp. 27362739, Aug. 2011.

[33] A. Schleunitz and H. Schift, "Fabrication of 3D nanoimprint stamps with continuous reliefs using dosemodulated electron beam lithography and thermal reflow," Journal of Micromechanics and Microengineering, vol. 20, no. 9, p. 095002, Sep. 2010.

[34] A. Schleunitz, V. A. Guzenko, M. Messerschmidt, H. Atasoy, R. Kirchner, and H. Schift, "Novel 3D microand nanofabrication method using thermally activated selective topography equilibration (TASTE) of polymers," Nano Convergence, vol. 1, no. 1, pp. 1-8, Feb. 2014.

[35] A. Schleunitz, C. Spreu, M. Vogler, H. Atasoy, and H. Schift, "Combining nanoimprint lithography and a molecular weight selective thermal reflow for the generation of mixed 3D structures," Journal of Vacuum Science \& Technology B, vol. 29, no. 6, p. 06FC01, Nov. 2011.

[36] R. Kirchner and H. Schift, "Mobility based 3D simulation of selective, viscoelastic polymer reflow using surface evolver," Journal of Vacuum Science \& Technology B, vol. 32, no. 6, p. 06F701, Nov. 2014.

[37] A. S. R. Kirchner, "Energy-based thermal reflow simulation for 3D polymer shape prediction using Surface Evolver," Journal of Micromechanics and Microengineering, vol. 24, no. 5, p. 055010 (7pp), 2014.

[38] H. Schift, "Nanoimprint lithography: 2D or not 2D? A review,” Appl. Phys. A, vol. 121, no. 2, pp. 415-435, Apr. 2015.

[39] S. Landis, V. Reboud, T. Enot, and C. Vizioz, "Three dimensional on $300 \mathrm{~mm}$ wafer scale nano imprint lithography processes," Microelectronic Engineering, vol. 110, pp. 198-203, Oct. 2013.

[40] S. V. Sreenivasan, P. Joseph, O. Abed, M. Grigas, A. Mallavarapu, and P. Ajay, "Fabricating Large Area Multi-tier Nanostructures,” US 2016/0308020 A1, 20Oct-2016.

[41] Y. Zhai, M. Palard, L. Mathew, M. Mustafa Hussain, C. Grant Willson, E. Tutuc, and S. K. Banerjee, "Fabrication of Three-Dimensional MIS NanoCapacitor Based on Nanoimprinted Single Crystal Silicon Nanowire Arrays," Micro and Nanosystems, vol. 4, no. 4, pp. 333-338, Nov. 2012.

[42] A. Cherala, M. Chopra, B. Yin, A. Mallavarapu, S. Singhal, O. Abed, R. Bonnecaze, and S. V. Sreenivasan, "Nanoshape Imprint Lithography for Fabrication of Nanowire Ultra-capacitors," IEEE Transactions on Nanotechnology, vol. PP, no. 99, pp. 1-1, 2016.

[43] P. Banerjee, I. Perez, L. Henn-Lecordier, S. B. Lee, and G. W. Rubloff, "Nanotubular metal-insulator-metal capacitor arrays for energy storage,” Nat Nano, vol. 4, no. 5, pp. 292-296, May 2009. 
[44] S. Ahn, J. Kim, and L. Guo, "Bilayer metal wire-grid polarizer fabricated by roll-to-roll nanoimprint lithography on flexible plastic substrate," Journal of Vacuum Science \& Technology B, vol. 25, no. 6, pp. 2388-2391, Nov. 2007.

[45] S. H. Ahn, S. Yang, M. Miller, M. Ganapathisubramanian, M. Menezes, J. Choi, F. Xu, D. J. Resnick, and S. V. Sreenivasan, "High-performance wire-grid polarizers using jet and Flash $^{\mathrm{TM}}$ imprint lithography," Journal of Micro/Nanolithography, MEMS, and MOEMS, vol. 12, no. 3, p. 1104, 2013.

[46] S. R. Min, H. N. Cho, Y. L. Li, S. K. Lim, S. P. Choi, and C. W. Chung, "Inductively coupled plasma reactive ion etching of titanium nitride thin films in a $\mathrm{Cl} 2 / \mathrm{Ar}$ plasma," Journal of Industrial and Engineering Chemistry, vol. 14, no. 3, pp. 297-302, May 2008.

[47] M. Shearn, X. Sun, M. D. Henry, A. Yariv, and A. Scherer, Advanced plasma processing: etching, deposition, and wafer bonding techniques for semiconductor applications. Intech, 2010.

[48] A. Crockett, M. Almoustafa, and W. Vanderlinde, "Plasma delayering of integrated circuits," Microelectronics Failure Analysis Desk Reference, vol. 4, pp. 243-25, 2004.

[49] S. Kalem, P. Werner, Ö. Arthursson, V. Talalaev, B. Nilsson, M. Hagberg, H. Frederiksen, and U. Södervall, "Black silicon with high density and high aspect ratio nanowhiskers," Nanotechnology, vol. 22, no. 23, p. 235307, 2011.

[50] H. V. Jansen, M. J. de Boer, R. Legtenberg, J. Elders, M. C. Elwenspoek, and J. H. J. Fluitman, "Process for producing micromechanical structures by means of reactieve ion etching," WO 1996008036 A1, 14-Mar1996.

[51] M. Suzuki, A. Takada, T. Yamada, T. Hayasaka, K. Sasaki, E. Takahashi, and S. Kumagai, "Lowreflectivity wire-grid polarizers multilayered by the glancing-angle-deposition technique," J. Nanophoton. 5(1), $051501 \quad$ (January 27, 2011). doi:10.1117/1.3543821.

[52] M. P. C. Watts, M. Little, E. Egan, A. Hochbaum, C. Johns, and S. Stephansen, "Wire grid polarizers fabricated by low angle deposition,” 2013, p. 86130E.

[53] M. P. C. Watts, M. Little, E. Egan, A. Hochbaum, C. Johns, and S. Stephansen, A Process for and Properties of Low Cost Wire Grid Polarizers. 2013.

[54] Y. J. Shin, C. Pina-Hernandez, Y.-K. Wu, J. G. Ok, and L. J. Guo, "Facile route of flexible wire grid polarizer fabrication by angled-evaporations of aluminum on two sidewalls of an imprinted nanograting," Nanotechnology, vol. 23, no. 34, p. 344018, Aug. 2012. 